\title{
The actions of $\alpha$-tocopherol and protein upon the incisor tooth of the rat, and the influence of vitamin $A$ upon $\alpha$-tocopherol activity
}

\author{
BY J. T. IRVING \\ Department of Experimental Odontology, and the Foint Dental Research Unit \\ of the Council for Scientific and Industrial Research and the University \\ of the Witwatersrand, Fohannesburg \\ (Received 11 December 1957)
}

In a previous paper (Irving \& Budtz-Olsen, 1955) it was reported that hake-liver oil, when included in a vitamin E-free diet, abolished the prophylactic action of $\alpha$-tocopherol. It was suspected that the large amount of vitamin $\mathrm{A}$ in the hake oil might be one of the factors responsible. In this paper results are presented to show that excess vitamin A can considerably modify the action of $\alpha$-tocopherol.

The prophylactic action of protein added to a vitamin E-free diet was also described in the previous paper, when it was found that the enamel organ, but not the tooth colour, was protected. In this paper, a comparison of the curative actions of $\alpha$-tocopherol and extra protein is reported. For tooth recovery protein was as effective as $\alpha$-tocopherol, but the dialuric-acid test remained positive in rats on the diet enriched in protein.

\section{EXPERIMENTAL}

Animals. The experimental animals were 270 young albino rats, descended from ancestors of the Wistar strain. Both sexes were used indiscriminately, as the same results were obtained with either. The rats were put on to the experimental diet when they weighed about $5 \circ \mathrm{g}$. Before that they and their mothers were fed on the Department's stock diet.

Diets. The diets were similar to those used by Irving \& Budtz-Olsen (I955), consisting of potato starch, dried brewer's yeast and cod-liver oil, sometimes with dried egg albumin. They were given without restriction. The compositions of the diets and the times of killing are shown in Table $\mathrm{I}$. The $\alpha$-tocopherol was administered as before, by mixing a $3 \mathrm{mg}$ tablet of $\alpha$-tocopheryl acetate (Ephynal, Roche Products Ltd) with $3 \mathrm{~g}$ of freshly made diet and giving it to the animal in the morning before it was fed. The vitamin $A$ was in a fish-liver oil concentrate and was administered by pipette to the animals daily.

General treatment. The animals were weighed twice weekly. They were killed between 20 and $\mathbf{r} 20$ days after going on to the diet (see Table I). Blood was taken for the dialuric-acid haemolysis test (György \& Rose, 1949). The state of pigmentation of the upper incisor teeth was noted. After the animals had been killed, the upper incisor teeth with the surrounding bone were removed. One tooth was fixed in 
Vol. 12

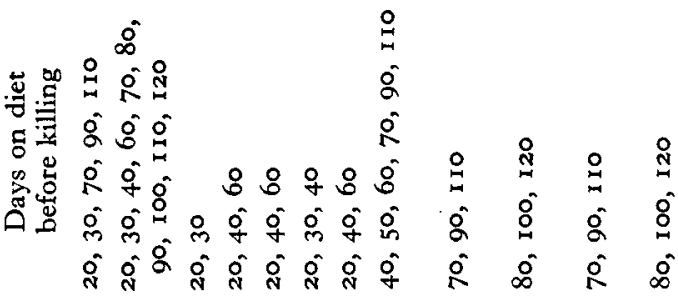

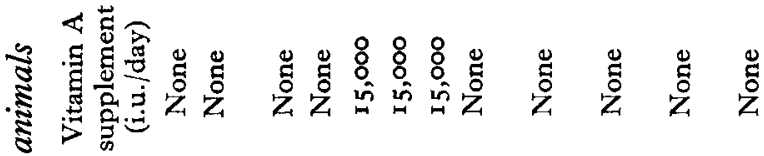

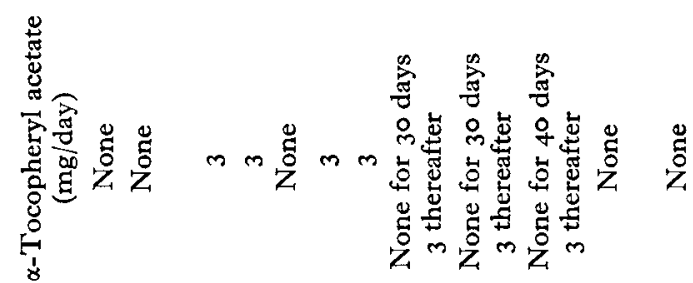

हैंة

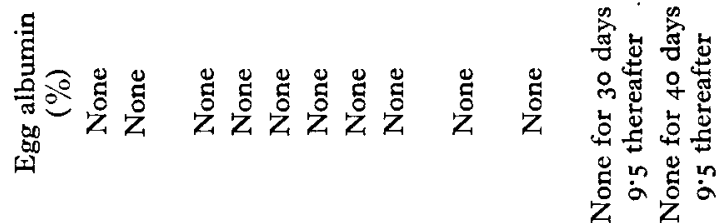

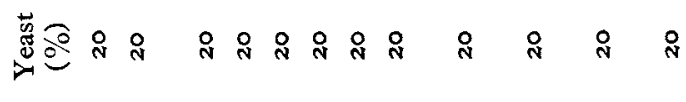

先

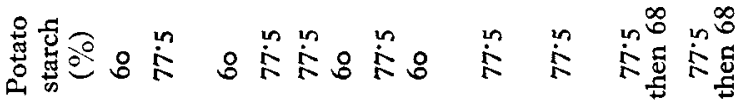

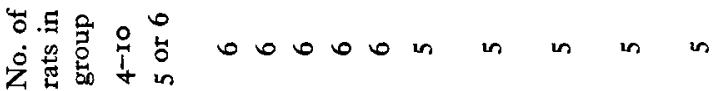

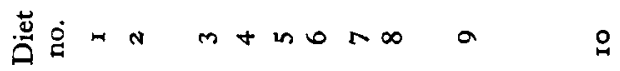


formol-saline and, after decalcification in a formic acid- $\mathrm{HCl}$ mixture, was cut in longitudinal section and stained with haematoxylin and eosin. The opposite tooth was fixed in Bouin's solution and decalcified with 10\% acetic acid. After longitudinal section, this tooth was stained for iron by Turnbull's method (ferrocyanide and $\mathrm{HCl}$ ), this procedure having been found the best for demonstrating the iron content of the ameloblasts.

\section{RESULTS}

As explained above, two experiments were planned, one to test the effects of excessive amounts of vitamin A upon the action of $\alpha$-tocopherol and the other to compare the prophylactic actions of $\alpha$-tocopherol and protein on the teeth of rats depleted of vitamin $\mathrm{E}$.

The initial experiments were done, as before, with $20 \%$ cod-liver oil in the diet. As the animals did not grow on this diet and as this high level of oil sometimes interfered with the action of the $\alpha$-tocopherol, the level was reduced in later experiments to $2.5 \%$. On this diet exactly the same tooth results were obtained, but the animals also gained in weight.

Since a study was made of iron staining in the ameloblasts, a few words must be said about the appearance and possible function of this element. Orange-coloured refractive granules are found in the ameloblasts on the more incisal side of the tall ameloblasts. These granules are probably the precursors of the orange-coloured pigment deposited on the tooth (Irving, 1952). Both these granules and also the pigment stain intensely for iron by the ferrocyanide- $\mathrm{HCl}$ technique. It is well known that the tooth pigment is rich in iron (Dam, Granados \& Maltesen, 1950), but in what form is still undecided. In vitamin $E$ deficiency the iron content of these ameloblasts is greatly reduced and they may contain none at all.

Diets I and 2: animals on vitamin E-free diets. These animals all showed in the enamel organ the degenerative changes previously described (Irving, 1942, 1956). Not all teeth were white at 20 days, but all were white thereafter. The dialuric-acid test was positive in all rats but two at 20 days. Some of the ameloblasts contained iron at 20 days, but all were iron-free or had only the merest trace later. On the $20 \%$ cod-liver oil diet the animals did not grow at all, but with the level of oil reduced to $2.5 \%$ growth occurred at an average rate of $0.6 \mathrm{~g} /$ day.

Diets 3 and 4 : animals on the basal diet receiving daily $3 \mathrm{mg} \alpha$-tocopheryl acetate. These animals all had teeth normal in colour and histology. The dialuric-acid test was uniformly negative. The growth rate was approximately the same as that of animals not getting $\alpha$-tocopherol.

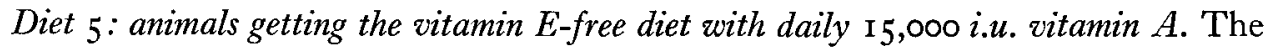
changes were just the same as in animals on the basal diet alone, save that no weight gains were made.

Diets 6 and 7 : animals getting the vitamin $E$-free diet with daily $3 \mathrm{mg} \alpha$-tocopheryl acetate and ${ }_{5} 5,000$ i.u. vitamin A. The effect of vitamin $\mathrm{A}$ was to reverse many of the curative effects of $\alpha$-tocopherol. The effects were more extreme in the animals on diet $6(20 \%$ cod-liver oil). On this diet, one tooth was white at 20 days, four out of six were white 
at 30 days and only one out of six was of normal colour at 40 days. The histological appearance was normal at 20 days, but four out of six were abnormal at both 30 and 40 days. The iron contents of the ameloblasts were not reduced to the same extent as in animals on the vitamin E-free diet, but there were many fewer iron-containing ameloblasts. All dialuric-acid tests were positive. Two animals had fractured legs at 40 days.

On diet 7 , the changes were not so severe. One tooth had lost pigment at 40 days and three were white at 60 days. Two teeth had abnormal histological changes at 40 days and three out of six at 60 days. The iron changes were less marked, but all the abnormal teeth had too few iron-containing ameloblasts. The losses of iron and of pigment went parallel. The dialuric-acid tests were positive in all rats. No weight gains, or only slight ones, were made over the whole experiment.

Diets 8 and 9: animals kept on the vitamin $E$-free diet for 30 or 40 days and then given $3 \mathrm{mg} \alpha$-tocopheryl acetate daily for up to 80 days. The results were the same with both of these groups and will be described together. The teeth were all white at the end of the depletion period. Not till 80 days later were all teeth properly pigmented.

As stated above, the enamel organs of the control rats had no iron, or the merest trace of it, in their ameloblasts (diets $I$ and 2). The recovery of iron in the ameloblasts was the earliest sign of $\alpha$-tocopherol action. Iron reappeared in small amounts in ameloblasts towards the formative end of the tooth ro days after dosage and from 30 days onwards ameloblasts with a normal iron content were found, but they were few in number. As the experiment progressed more and more iron-containing ameloblasts were to be seen, the number corresponding to the degree of recovery of the enamel organ.

The histological recovery was rather like the development of the pathological change in reverse. Apart from the increase in iron content of the ameloblasts, no change at all was seen till $\alpha$-tocopherol dosage had lasted 40 days, in which time the tooth had largely replaced itself. From then on, new and normal enamel organ gradually extended further forward, the outer enamel organ recovering first, and by 40 days in a few rats this part of the enamel organ extended to where it fused with the gingival epithelium, but the ameloblasts regressed prematurely to a flattened form. It was noted that the teeth that had not recovered pigmentation, as seen externally, were those in which fibrous tissue still replaced the enamel organ towards the incisal end of the tooth. With the passage of time, normal ameloblasts were found further and further forward, but, even at 80 days after $\alpha$-tocopherol dosage had begun, not all enamel organs were entirely normal, though the tooth colour had quite recovered.

The dialuric-acid test was faintly positive (at $24 \mathrm{~h}$ ) after 10 days' dosing with $\alpha$-tocopherol, but was consistently negative after that. The addition of $\alpha$-tocopherol made no difference to the growth rate, which was on an average $0.7 \mathrm{~g} /$ day over the whole experiment.

Diets 9 and 10: animals on the vitamin E-free diet for 30 or 40 days and then given extra protein. At the end of the depletion period all teeth were white.

The changes were the same in both groups and almost exactly paralleled those in rats getting $\alpha$-tocopherol after the depletion period. The tooth colour was not restored 
in all rats till 80 days later. The pattern of enamel-organ recovery was exactly the same as in the rats dosed with $\alpha$-tocopherol, and even at 80 days some rats showed a normal outer enamel epithelium, but the ameloblasts regressed too early. The iron content of individual ameloblasts was normal but, until and even at 80 days, there were abnormally few iron-containing cells. The dialuric-acid test was consistently positive. The addition of protein increased the growth rate, which rose on an average to I.7 g/day.

\section{DISCUSSION}

It is evident from the above results that excessive vitamin $A$ in the diet can interfere with the protective action of $\alpha$-tocopherol on the teeth to a considerable extent and can also cause reversal of the dialuric-acid test. In a previous paper (Irving \& BudtzOlsen, I955) the danger of using large quantities of liver oils in studies of this type was stressed; in fact with the diet used by us such large quantities are unnecessary, since the typical histological changes in the enamel organ can be produced on a diet containing $2.5 \%$ cod-liver oil in as short a time as 20 days.

It is difficult to understand this action of vitamin A. Excessive intakes of vitamin A combined with an otherwise normal diet have no effect upon the enamel organ (Irving, I949), but under the experimental conditions described appear to destroy $\alpha$-tocopherol or prevent its action generally, as shown by the positive dialuric-acid tests. The two vitamins were given by mouth, but not in the same medium; some interaction may take place in the stomach. Only further work can elucidate this problem.

The histological effects of the curative action of $\alpha$-tocopherol or protein on teeth have not been previously reported. Granados, Mason \& Dam (I945) found that normal pigment was again deposited on the incisor tooth some weeks after giving $\alpha$-tocopherol to depleted rats. Moore (r 949 ) likewise found that after a depletion period $\alpha$-tocopherol restored the tooth colour in from 4 to 7 weeks. If tooth eruption is taken into account, the curative changes must have begun some time before pigment was seen on the visible part of the tooth, and histological examination showed that recovery after treatment with $\alpha$-tocopherol was much quicker than the findings of Granados et al. (1945) and Moore (1949) would indicate. From the iron content of the ameloblasts curative action could be detected Io days after dosage had been begun. 'This effect is paralleled by the quick curative action of vitamin D (Irving, I944) and vitamin A (Schour, Hoffman \& Smith, I94I) on teeth in rickets and avitaminosis A. The haemolysis test likewise was negative after ro days' dosing. The reason why the teeth continue white when some ameloblasts have recovered their iron content has already been explained (Irving, 1952). Further forward, where the enamel organ is still missing and replaced by fibrous tissue, macrophages remove the pigment from the enamel surface as the tooth erupts. The subsequent repair of the enamel organ was much slower, and even at 80 days, when the tooth had replaced itself at least once, the enamel organ was not always normal.

Moore (I949) put rats on to a high-protein, vitamin E-free diet and found that the upper teeth were not protected, but the lower incisors maintained their colour. Other 
writers have reported a partial protection of tooth colour by protein. No one, as far as I know, has transferred rats after a depletion period on a low-protein, vitamin Efree diet to one containing more protein. The dialuric-acid test remained positive in all animals up to 80 days later, but the tooth recovery was exactly the same as in the $\alpha$-tocopherol-treated rats, including recovery of the iron content of the ameloblasts. It may be noted that $\alpha$-tocopherol and protein are equally active in protecting the liver from necrosis. In a previous paper (Irving \& Budtz-Olsen, 1955) it was reported that protein protected only the enamel organ but not the tooth colour. The recovery of both of these in the later experiments was probably due to the use of $2.5 \%$ cod-liver oil in the diet, instead of $20 \%$ as previously.

It has been suggested (Dam et al. I950) that $\alpha$-tocopherol plays an important part in the iron metabolism of the tooth, as witnessed by its protective effect on the pigment. Though this is undoubtedly so, it would appear that this role is not specific to this vitamin. Any condition causing atrophy of the enamel organ would presumably interfere with its iron metabolism. Thus in avitaminosis A or fluorine intoxication, when the enamel organ atrophies, white teeth are produced. It was found, in prolonged experiments on diets free of $\alpha$-tocopherol, that the enamel organ might atrophy to such an extent that the cells producing the enamel matrix were involved, so that the enamel was not only white but also not properly matured and acidinsoluble in histological preparations. It would thus appear probable that the entire enamel organ requires $\alpha$-tocopherol for its maintenance, and not only for its pigmentproducing properties. The non-specificity of $\alpha$-tocopherol in the iron metabolism of the ameloblast is also shown by the fact that protein will restore the iron content just as well. The iron level in the diet does not influence the depigmentation of the teeth of rats on vitamin E-free diets (Granados \& Dam, 1947).

Finally, it should be pointed out that whereas bone requires protein, no matter what the dietary level of $\alpha$-tocopherol, the enamel organ apparently needs adequate protein for its maintenance only if the $\alpha$-tocopherol level of the diet is low.

\section{SUMMARY}

I. Albino rats weighing about $5^{\circ} \mathrm{g}$ were placed on a vitamin E-free diet of potato starch, dried brewer's yeast and various amounts of cod-liver oil. Some rats were given extra protein and others received large doses of vitamin A. The positive control animals were given $3 \mathrm{mg} \alpha$-tocopheryl acetate daily.

2. The protective action of $\alpha$-tocopherol upon the incisal enamel organ and tooth colour of rats on vitamin E-free diets was reversed in many rats by the simultaneous daily administration of $\mathrm{r}_{5}, 000 \mathrm{i.u}$. vitamin $\mathrm{A}$, and the dialuric-acid test became positive. This finding may explain in part some of the effects obtained with diets high in fish oil, which interferes with $\alpha$-tocopherol action.

3. The curative action of extra protein in the diet upon the incisor teeth of rats depleted of vitamin $\mathrm{E}$ was compared with that of $\alpha$-tocopherol. The changes induced by these two agencies were identical, both tooth colour and enamel-organ structure being restored to normal, or nearly so, during the experimental period. The rats dosed 
with $\alpha$-tocopherol had negative dialuric-acid tests, but those of the protein-treated rats remained consistently positive.

I thank the Marine Oil Refiners of Africa Ltd for a gift of a vitamin A concentrate, and Roche Products Ltd for gifts of Ephynal. I am also grateful to Dr C. C. Solomons for carrying out the dialuric-acid haemolysis tests.

\section{REFERENCES}

Dam, H., Granados, H. \& Maltesen, L. (1950). Acta physiol. scand. 21, I24. Granados, H. \& Dam, H. (1947). F. dent. Res. 26, 47 r.

Granados, H., Mason, K. E. \& Dam, H. (I945). F. dent. Res. 24, 197.

György, P. \& Rose, C. S. (r949). Ann. N.Y. Acad. Sci. 52, Art. 3, p. 23 I.

Irving, J. T. (1942). Nature, Lond., 150, 122.

Irving, J. T. (1944). F. Physiol. 103, 9.

Irving, J. T. (1949). F. Physiol. 108, 92.

Irving, J. T. (1952). Nature, Lond., 170, 573.

Irving, J. T. (1956). F. dent. Res. 35, 930.

Irving, J. T. \& Budtz-Olsen, O. E. (1955). Brit. F. Nutr. 9, 301.

Moore, T. (1949). Ann. N.Y. Acad. Sci. 52, Art. 3, p. 206.

Schour, I., Hoffman, M. M. \& Smith, M. C. (194I). Amer. F. Path. 17, 529. 